\title{
Significance of CD44 expression in head and neck cancer: a systemic review and meta-analysis
}

\author{
Jianqiang Chen, Jianding Zhou, Jie Lu, Hua Xiong, Xueli Shi and Liang Gong*
}

\begin{abstract}
Background: CD44 has been reported to be involved with tumor growth and metastasis and has also been implicated as a CSC marker in head and neck squamous cell cancer (HNSCC). However, the prognostic value of CD44 still remains controversial; hence, we investigated the correlation between CD44 and the clinicopathological features of HNSCC by meta-analysis.

Methods: A comprehensive search was performed using PubMed, ISI web of Science and China National Knowledge Infrastructure (CNKI) up to April 2013. Only studies with immunohistochemical staining of HNSCC were considered. Data on TNM classification, tumor grade, disease free survival and 3- or 5-year overall survival rate were extracted.

Results: Thirty studies with 2102 patients met the inclusion criteria for the meta-analysis. Fifteen studies used anti-pan-CD44 antibody, 9 used anti-CD44-v6 antibody, 2 used anti-CD44-v3 and 2 used anti-CD44s antibody, 1 used anti-CD44-v9, and 1 used anti-CD44-v6,-v3 and -v4-5 simultaneously. The total percentage of CD44 expression was $57.8 \%$, with $49.3 \%$ in oral cancer patients, $66.4 \%$ in pharynx and $54.7 \%$ in larynx cancer patients expressing CD44. No significant correlation between clinical features and CD44 expression was revealed for oral cancer patients, but CD44 was shown to be associated with advanced T categories (larynx: RR $=1.33,95 \% \mathrm{Cl} 1.01-1.76$; larynx \& pharynx $R R=1.21,95 \% \mathrm{Cl} 1.08-1.35$ ), worse N categories (larynx: $\mathrm{RR}=2.53,95 \% \mathrm{Cl} 1.99-3.21$; larynx \& pharynx $R R=1.95,95 \% \mathrm{Cl} 1.35-2.82$ ), higher tumor grades (larynx \& pharynx $R R=1.71,95 \% \mathrm{Cl} 1.04-2.79$ ) and 5-year OS rates (larynx: $R R=0.62,95 \% \mathrm{Cl} 0.47-0.83$; larynx \& pharynx $\mathrm{RR}=0.66,95 \% \mathrm{Cl} 0.47-0.94$ ) in patients with laryngeal and pharyngolaryngeal cancer. In stratified analysis, pan-CD44 and CD44-v6 expression were both correlated with 5-year OS rate of patients with laryngeal (CD44: $R R=0.66,95 \% \mathrm{Cl}$ 0.46-0.95; $C D 44-v 6 \mathrm{RR}=0.53,95 \% \mathrm{Cl}$ 0.37-0.77) and pharyngolaryngeal cancer (CD44: $\mathrm{RR}=0.56,95 \% \mathrm{Cl} 0.34-0.93 ; \mathrm{CD} 44-\mathrm{v} 6 \mathrm{RR}=0.53,95 \% \mathrm{Cl} 0.37-0.77)$.
\end{abstract}

Conclusions: Our analysis suggested that CD44 is related to worse T category, N category, tumor grade and prognosis, in pharyngeal and laryngeal cancer, but no clear association was revealed between CD44 expression and oral cancer.

Keywords: Pan-CD44, CD44-v6, Head and neck cancer, Prognosis

\section{Background}

Although the treatment for head and neck cancer is improving rapidly, head and neck cancer is still the sixth most common cancer worldwide, mainly because it is usually difficult to diagnosis at an early stage [1]. The histopathological types and developmental origins of cancers in the head and neck (oral, pharynx and larynx) are highly homologous, and ninety percent of the tumors in the head

\footnotetext{
* Correspondence: 11118118@zju.edu.cn

Department of Otorhinolaryngology, Affiliated Cixi Hospital of Wenzhou Medical, College, Cixi 315300, China
}

\section{Biomed Central}

and neck are squamous-cell carcinomas (HNSCCs), which present as aggressive and recurrent malignancies [2]. Therefore, understanding the precise biological behavior of HNSCC in the head and neck is very important for early diagnosis and outcome prediction.

Currently, the most accepted prognostic factors are TNM classification, which relies on the tumor size, and metastasis [1]. However, the TNM system cannot distinguish aggressive tumors from nonaggressive tumors of the same size. Therefore, it would be very beneficial to find one or more bio-markers for the prediction of the 
biological behavior of HNSCCs. Recently, a small population of cancer cells, referred to as cancer stem cells (CSCs), was revealed to account for tumor initiation, relapse and resistance to chemo- or radiotherapy; thus, eradicating CSCs is considered critical in cancer therapy $[3,4]$. The CSC hypothesis has also been coined for HNSCC in the head and neck; some cell surface markers have been reported as CSC markers in HNSCC cancers, such as CD44, CD133, ALDH1 and ABCG2 [5-7], and high expression of these markers is usually considered an indicator of poor prognosis. Among them, CD44 is the most reported CSC marker in HNSCC [8-10].

The CD44 receptor is a typeItransmembrane glycoprotein that was initially identified as a leukocyte antigen $[11,12]$. The alternative splicing of variable exons of CD44 results in abundant variants, which are denoted $\mathrm{CD} 44 \mathrm{v}$, and the isoform with no variable exons in the mRNA is named CD44 standard (CD44s) [13]. The smallest, standard isoform is CD44s, which is generally expressed on vertebrate cells, while CD44v is only expressed on some epithelial cells $[12,13]$. CD44 is the major hyaluronan (HA) receptor [14], and CD44 bound to HA has been proven to participate in various tumor biological activities, including tumor progression, metastasis and proliferation $[15,16]$. CD44 plays a critical role in cell migration, with involvement in multiple steps. Once activated, the cytoplasmic tail of CD44 interacts with the actin cytoskeleton, and $\mathrm{CD} 44$ is induced to the leading edge of migrating cells. Then, CD44 binds with CD62 on the endothelial cells, and thereafter, the migrating cells roll on the endothelial cells. This process is the initial step of cell migration called extravasation [12,17,18]. Although nearly all evidence has shown a negative role of CD44 in tumor progression, some conflicting reports have found a positive prognostic value of CD44 in head and neck cancers, especially in oral cancer [19-22], which indicates that some information regarding CD44 is still uncovered. Therefore, we present here a systemic review and meta-analysis of published studies on the association of CD44 expression with clinicopathological features in patients with head and neck cancer.

\section{Methods}

\section{Literature search and eligibility criteria}

A systematic literature search of the electronic database PubMed, ISI Web of Science and China National Knowledge Infrastructure (CNKI) up to April 2013 was performed. A random combination of the following terms was used for the search: 'CD44', 'oral', 'larynx or laryngeal', 'pharynx, nasopharynx, oralpharynx, hypopharynx or pharyngeal', and 'tumor, neoplasm, cancer or carcinoma'. The titles and abstracts of potential references were manually examined to exclude irrelevant publications, and all of the remaining literature on the topic of interest was reviewed for additional pertinent studies.

The studies included in this meta-analysis were either randomized controlled studies (RCTs) or observational studies (case-control or cohort) that evaluated the relationship between CD44 expression and clinicopathological features or prognosis in head and neck cancer. Eligible studies met the following criteria: (a) proven diagnosis of HNSCC in head and neck (oral cavity, larynx or pharynx); (b) the CD44-positive group was defined by an immunohistochemistry method; (c) the correlation of CD44 with clinicopathological features and survival outcome (either disease free survival or overall survival) was analyzed; (d) HR/logHR and 95\% confidence interval (CI)/standard error (SE) or crude data were provided; and (e) the articles were written in English or Chinese.

All information, including the titles and abstracts of the potential literature, were read by two reviewers (L.G and J.C) independently to exclude irrelevant publications. Then, the full texts of the extracted articles were carefully examined for comprehensive evaluation. Disagreements were resolved by discussion with a third reviewer (J.Z). Moreover, when multiple studies contained overlapping data, the one with the largest data set or newest data was included, and the others were excluded. Simultaneously, the references of extracted articles were also manually searched to avoid missing relevant studies. If the full text was unavailable, we contacted the authors for the data needed for the meta-analysis.

\section{Data extraction and quality assessment}

All data from the eligible studies were extracted by two independent reviewers (J.Z and J.L) with a predefined table (Additional file 1: Table S1). Data tables were designed to extract all relevant data from texts, tables and figures, including author, year, country, patient number, detection method, duration of follow-up, $\mathrm{T}$ category, $\mathrm{N}$ category, distant metastasis, the antibody used in the article, positive rates of $\mathrm{CD} 44$ over-expression, disease free survival rate (DFS) and 3-/5- year overall survival (OS) rates. Because some articles showed survival data indirectly with a Kaplan-Meier curve, the software GetData Graph Digitizer 2.24 (http://getdata-graph-digitizer.com/) was applied to digitize and extract the data.

The cut-off score of the CD44 positive group varied among the different studies; we defined the CD44 positive group according to the original articles. Because several studies gave data on the 3-year survival outcome while others gave data on 5-year survival outcome, we analyzed both the 3 -and 5 -year overall survival rates here.

\section{Statistical analysis}

Stata version 11 (StataCorp LP, TX) was used in this metaanalysis. The statistical process was performed according 
to the guidelines proposed by the Meta-Analysis of Observational Studies in Epidemiology group. Relative risk (RR) with a 95\% confidence interval (95\% CI) was calculated using Review Manager 4.2. The heterogeneity among the studies was measured using the $\mathrm{Q}$ test and $\mathrm{I}^{2}$ test. A fixed or random model was used depending on the heterogeneity analysis. The potential for publication bias was assessed by the Funnel plots and Egger's regression test. $P$ values $<0.05$ were considered statistically significant. All P values above are two tailed. Subgroup analyses were performed to investigate the value of CD44 expression as a prognostic indicator for HNSCC patients in studies of different organs, geographical locations, sample sizes and follow-up durations. Among the variants of CD44, anti-pan-CD44 antibody and anti-CD44-v6 antibody were the most applied in the articles; therefore, we also analyzed all of the parameters stratified by pan-CD44 and CD44-v6. Sensitivity analyses were also performed by excluding each study individually. In addition, this meta-analysis was also addressed with standard PRISMA checklist and diagram (Additional files 2 and 3).

\section{Results}

\section{Search results}

Using the search strategy above, 474 articles were retrieved initially. After reviewing the titles and abstracts, 251 of those articles were excluded because they described non-human experiments or non-head and neck cancerrelated studies or were non-original articles (reviews, letters). Of the remaining articles, 169 were excluded because they did not provide clinicopathological or survival rate data. Then, a secondary screen was performed that ruled out 24 studies without detailed data for analysis because, for example, the numbers of patients with high and low CD44 expression were not given. Eventually, a total of 30 studies were included in the present meta-analysis with approximately 2102 participants (Figure 1).

\section{Description of eligible studies}

The characteristics of all included studies are listed in Table 1. Among the 30 studies analyzed, 20 were launched in Asia (China and Japan) and 10 in Europe or the USA. A total of 2102 patients with a median cohort size for each study of 58.5 (range 26 to 154) were included, and the mean follow-up time for the studies was 68.5 months (range 36 - 271 months). The TNM stage or tumor grade were reported in 24 studies, and patient outcome was reported in 15 studies (DFS and OS were presented in 5 and 12 articles, respectively). The median percentage of patients with CD44 positive expression was $57.8 \%$ (range $10.2-75.4 \%$ ); for patients with oral cancer, pharynx cancer, and larynx cancer, the median percentages of patients with CD44 positive expression were $49.3 \%$ (range 10.2 - 70.9\%), 66.4\% (57.5 - 75.4\%)

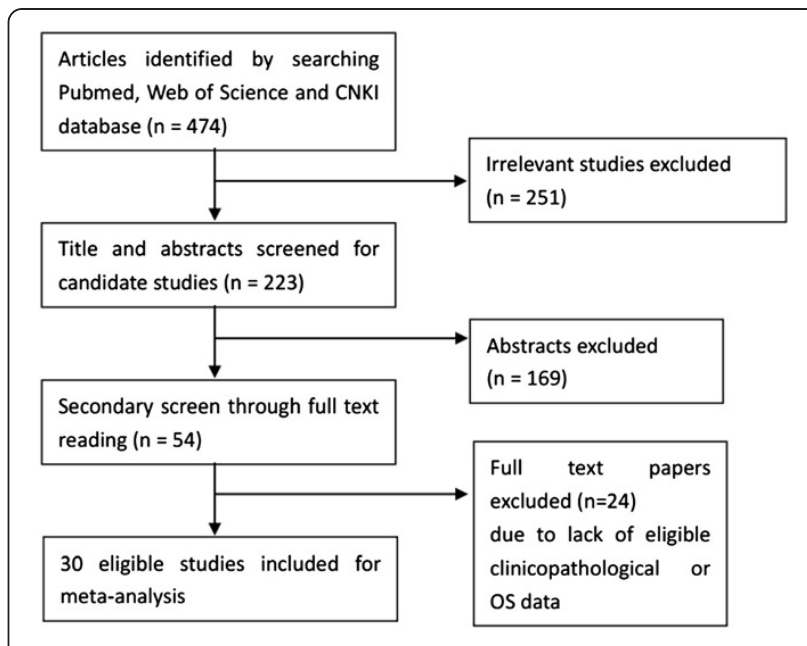

Figure 1 Flow chart for the selection of included articles.

and 54.7\% (12 - 82.9\%), respectively. All studies applied an immunochemistry staining method to detect CD44. expression: anti-pan-CD44 antibody was used in 15 studies [2,19-32], which detected all variations of CD44, anti-CD44-v6 antibody was used in 9 studies [33-41], anti-CD44-v3 antibody and anti-CD44s antibody were used together in 2 studies [42-45], anti-CD44-v9 was used in 1 study [46], and 1 study assessed CD44-v6,-v3 and -v4-5 simultaneously [47]. The most common cut-off values designating CD44 expression were cell membrane stainings of $50 \%(n=16)$ and $25 \%(n=5)$. Most of the included patients received surgical therapy, while 50 patients were treated with radiotherapy [21,42], 111 patients were given combined radiotherapy and surgery, and two patients received neoadjuvant chemotherapy $[21,43]$.

\section{Relationship of CD44 with clinical features and patient survival}

Additional file 4: Table S2 shows the summary RR of the clinicopathological features in patients with CD44 high and low expression. The pool analysis found a minimally significant association between CD44 and clinical features; the $\mathrm{N}$ grade $(\mathrm{RR}=1.39,95 \% \mathrm{CI} 1.07-1.81)$ and 3-year OS rate $(R R=0.76,95 \%$ CI 0.59-0.99) were negatively correlated with CD44 expression. Egger's test did not show any publication bias for the above data (Additional file 1: Table S1). Because CD44 expression may be organ specific, we performed a stratified analysis of oral, larynx and pharyngolaryngeal cancer. Although no significant relationship was found between clinical features and CD44 expression in oral cancer, CD44 expression was shown to be associated with worse $\mathrm{T}$ categories (larynx: $\mathrm{RR}=1.33,95 \%$ CI 1.01-1.76; larynx \& pharynx $\mathrm{RR}=1.21$, 95\% CI 1.08-1.35; Additional file 5: Figure S1), worse N categories (larynx: $\mathrm{RR}=2.53,95 \%$ CI 1.99-3.21; larynx \& pharynx $\mathrm{RR}=1.95$, 95\% CI 1.35-2.82; Additional file 6: 


\begin{tabular}{|c|c|c|c|c|c|c|c|c|c|c|c|c|c|c|c|}
\hline & & & $\begin{array}{c}\text { T category } \\
(\mathrm{T} 3,4 \text { vs. } \mathrm{T} 1,2)\end{array}$ & & $\begin{array}{l}\text { N category } \\
\text { (H vs. L) }\end{array}$ & & $\begin{array}{l}\text { M category } \\
\text { (H vs. L) }\end{array}$ & & $\begin{array}{c}\text { Grade } \\
\text { (G3 vs. G1,2) }\end{array}$ & & $\begin{array}{c}\text { DFS } \\
\text { (death vs. survive) }\end{array}$ & & $\begin{array}{c}\text { OS } 3 \text { year } \\
\text { (death vs. survive) }\end{array}$ & & $\begin{array}{l}\text { OS } 5 \text { year } \\
\text { (death vs. } \\
\text { survive) }\end{array}$ \\
\hline & & N1 & $\mathrm{RR}(95 \% \mathrm{Cl})$ & N2 & $\mathrm{RR}(95 \% \mathrm{Cl})$ & N3 & $\mathrm{RR}(95 \% \mathrm{Cl})$ & N4 & $\mathrm{RR}(95 \% \mathrm{Cl})$ & N5 & $\mathrm{RR}(95 \% \mathrm{Cl})$ & N6 & $\mathrm{RR}(95 \% \mathrm{Cl})$ & N7 & $\mathrm{RR}(95 \% \mathrm{Cl})$ \\
\hline Over all & & 13 & $1.15(0.97,1.35)$ & 23 & $1.39(1.07,1.81)$ & 4 & $1.79(0.76,4.26)$ & 7 & $1.47(1.00,2.14)$ & 5 & $1.50(0.83,2.71)$ & 10 & $0.76(0.59,0.99)$ & 12 & $0.76(0.55,1.05)$ \\
\hline \multicolumn{16}{|l|}{ Cancer type } \\
\hline Oral & & 2 & $0.75(0.48,1.16)$ & 9 & $0.82(0.54,1.25)$ & 2 & $1.99(0.99,3.99)$ & 2 & $0.91(0.50,1.67)$ & 4 & $1.86(1.47,2.37)$ & 3 & $0.85(0.49,1.47)$ & 5 & $0.91(0.46,1.78)$ \\
\hline Larynx & & 8 & $1.33(1.01,1.76)$ & 11 & $2.53(1.99,3.21)$ & - & - & 4 & $2.13(0.99,4.58)$ & - & - & 5 & $0.87(0.62,1.23)$ & 5 & $0.62(0.47,0.83)$ \\
\hline Pharynx \& Larynx & & 11 & $1.21(1.08,1.35)$ & 14 & $1.95(1.35,2.82)$ & 2 & $1.77(0.13,23.59)$ & 5 & $1.71(1.04,2.79)$ & 1 & $0.53(0.29,0.97)$ & 7 & $0.72(0.52,0.99)$ & 7 & $0.66(0.47,0.94)$ \\
\hline \multicolumn{16}{|l|}{ Geographic area } \\
\hline \multirow[t]{4}{*}{ Asia } & Over all & 9 & $1.39(1.17,1.64)$ & 16 & $1.81(1.26,2.61)$ & 3 & $1.82(0.59,5.63)$ & 6 & $1.61(1.01,2.57)$ & 2 & $0.98(0.28,3.4)$ & 4 & $0.71(0.56,0.89)$ & 4 & $0.8(0.57,1.14)$ \\
\hline & Oral & - & & 3 & $0.75(0.10,5.62)$ & 1 & $2.03(0.99,4.17)$ & 1 & $0.72(0.02,4.33)$ & 1 & $1.87(0.9,3.88)$ & - & - & - & - \\
\hline & Larynx & 6 & $1.60(1.14,2.25)$ & 10 & $2.39(1.65,3.45)$ & - & - & 4 & $2.13(0.99,4.58)$ & - & - & 3 & $0.77(0.66,0.9)$ & 3 & $0.69(0.52,0.91)$ \\
\hline & Larynx \& pharynx & 9 & $1.39(1.17,1.64)$ & 13 & $1.98(1.33,2.95)$ & 2 & $1.77(0.13,23.59)$ & 5 & $1.71(1.04,2.79)$ & 1 & $0.53(0.29,0.97)$ & 4 & $0.71(0.56,0.89)$ & 4 & $0.8(0.57,0.94)$ \\
\hline \multirow[t]{4}{*}{ Europe \& USA } & Over all & 3 & $0.88(0.76,1.02)$ & 6 & $0.90(0.68,1.20)$ & 1 & $1.46(0.09,22.93)$ & 1 & $1.03(0.56,1.92)$ & 2 & $3.08(0.74,12.78)$ & 6 & $0.78(0.48,1.27)$ & 8 & $0.64(0.35,1.16)$ \\
\hline & Oral & 1 & $0.57(0.30,1.11)$ & 5 & $0.73(0.52,1.02)$ & 1 & $1.46(0.09,22.93)$ & 1 & $1.03(0.56,1.92)$ & 2 & $3.08(0.74,12.78)$ & 3 & $0.85(0.49,1.47)$ & 5 & $0.90(0.46,1.78)$ \\
\hline & Larynx & 2 & $0.96(0.85,1.08)$ & 1 & $1.85(1.07,3.18)$ & - & - & - & - & - & - & 2 & $0.96(0.24,3.88)$ & 2 & $0.46(0.29,0.72)$ \\
\hline & Larynx \& pharynx & 2 & $0.96(0.85,1.08)$ & 1 & $1.85(1.07,3.18)$ & - & - & - & - & - & - & 3 & $0.61(0.15,2.5)$ & 3 & $0.36(0.23,0.57)$ \\
\hline \multirow[t]{2}{*}{ Oral } & Pan-CD44 & 2 & $0.75(0.48,1.16)$ & 3 & $0.58(0.37,0.92)$ & 2 & $1.99(0.99,3.99)$ & 2 & $0.91(0.5,1.67)$ & 2 & $1.65(1.68,2.13)$ & 3 & $0.85(0.49,1.47)$ & 4 & $0.69(0.32,1.52)$ \\
\hline & CD44-6 & - & - & 2 & $0.79(0.29,2.12)$ & - & - & - & - & - & - & - & - & - & - \\
\hline \multirow[t]{2}{*}{ Larynx } & Pan-CD44 & 5 & $1.25(0.90,1.73)$ & 6 & $2.83(2.01,3.98)$ & 2 & - & 4 & $2.13(0.99,4.58)$ & - & - & 5 & $0.87(0.62,1.23)$ & 3 & $0.66(0.46,0.95)$ \\
\hline & CD44-6 & 2 & $1.34(0.99,1.82)$ & 4 & $1.92(1.39,2.64)$ & - & - & - & - & - & - & - & - & 2 & $0.53(0.37,0.77)$ \\
\hline \multirow[t]{2}{*}{ Larynx \& pharynx } & Pan-CD44 & 6 & $1.23(0.92,1.65)$ & 7 & $2.74(1.98,3.81)$ & 1 & $6.65(0.93,47.63)$ & 4 & $2.13(0.99,4.58)$ & 1 & $0.53(0.29,0.97)$ & 6 & $0.794(0.56,1.1)$ & 4 & $0.56(0.34,0.93)$ \\
\hline & CD44-6 & 3 & $1.15(0.90,1.48)$ & 5 & $1.47(0.90,2.42)$ & 1 & $1.03(0.94,1.13)$ & - & - & - & - & - & - & 2 & $0.53(0.37,0.77)$ \\
\hline \multirow[t]{2}{*}{ Sample size ${ }^{a}$} & $<58.5$ & 4 & $1.79(0.82,3.89)$ & 10 & $1.388(0.83,2.33)$ & 1 & $6.65(0.93,47.63)$ & 3 & $1.34(0.5,3.58)$ & 3 & $1.71(0.44,6.69)$ & 3 & $0.34(0.21,0.54)$ & 6 & $0.55(0.22,1.37)$ \\
\hline & $\geq 58.5$ & 9 & $1.03(0.91,1.17)$ & 13 & $1.40(1.01,1.95)$ & 3 & $1.62(0.87,3.03)$ & 4 & $1.62(0.91,2.88)$ & 2 & $1.65(1.28,2.13)$ & 7 & $0.91(0.69,1.2)$ & 6 & $0.80(0.57,1.13)$ \\
\hline \multirow{2}{*}{$\begin{array}{l}\text { Follow time } \\
\text { (month) }^{\mathrm{b}}\end{array}$} & $<68.5$ & 7 & $1.04(0.89,1.20)$ & 8 & $1.29(0.80,2.10)$ & 2 & $4.51(0.96,21.13)$ & 5 & $1.42(0.96,2.08)$ & 5 & $1.50(0.83,2.71)$ & 7 & $0.88(0.66,1.17)$ & 8 & $0.89(0.62,1.28)$ \\
\hline & $\geq 68.5$ & 6 & $1.37(0.94,2.01)$ & 15 & $1.45(1.03,2.05)$ & 2 & $1.28(0.36,4.50)$ & 2 & $1.27(0.11,14.01)$ & - & - & 3 & $0.39(0.25,0.62)$ & 4 & $0.43(0.29,0.65)$ \\
\hline
\end{tabular}


Figure S2), higher tumor grades (larynx \& pharynx $\mathrm{RR}=1.71$, 95\% CI 1.04-2.79; Additional file 7: Figure S3), worse 3-year survival rates (larynx \& pharynx $R R=0.72$, 95\% CI 0.52-0.99) and worse 5-year survival rates (larynx: $\mathrm{RR}=0.62,95 \%$ CI 0.47 - 0.83; larynx \& pharynx RR = 0.66, 95\% CI 0.47 - 0.94; Figure 2) in laryngeal and pharyngolaryngeal cancer. Here, Egger's test showed that a publication bias was present for the T category (larynx: $p=0.033$; larynx \& pharynx: $p=0.033$ ) and tumor grade (larynx \& pharynx: $p=0.01$ ), but there was no evidence of publication bias for the 3-year (larynx \& pharynx: Egger's test $p=0.454$; Begg's test $p=0.76$ ) and 5-year overall survival rates (larynx: Egger's test $p=0.137$ Begg's test $p=1$; larynx \& pharynx: Egger's test $p=0.355$ Begg's test $p=0.548$ Figure 3). Sensitivity analyses also revealed the stability of our results (Additional file 8: Figure S4), indicating that CD44 expression was a prognostic factor for laryngeal and pharyngeal HNSCC patients .

\section{Subgroup analyses}

Additional file 4: Table S2 presents the detailed results of the subgroup analyses. In addition to the analysis of expression in specific organs, which was presented above, we also evaluated the data of studies in different geographic locations and the data of studies using different antibodies. The results revealed that CD44 expression predicted worse 5-year OS in HNSCC patients of the pharynx and larynx and that this result was similar for the studies in Asia ( $R R=0.8,95 \%$ CI 0.57 - 0.94) and Europe/USA ( $R R=0.36$, 95\% CI $0.23-0.57)$. However, CD44 expression was not found to be a significant predictor of 3-year OS in European patients $(R R=0.61,95 \%$ CI 0.15 - 2.5) as one Spanish study showed the opposite result from the other European studies [20]. In consideration of the clinical features, CD44 expression was also associated with larger tumor size $(R R=1.39,95 \% \mathrm{CI}$ 1.17 - 1.64) and lymph node metastasis $(\mathrm{RR}=1.98,95 \% \mathrm{CI}$ 1.33 - 2.95) in pharyngolaryngeal cancer of Asian patients; however, this phenomenon was not found in European patients, which may due to the limited number of European articles. Moreover, CD44 expression did not show significant correlation with OS rate or any clinical characteristics in Asian or European oral cancer patients. Because CD44 has many variants that have been reported with distinct biological functions, we divided the studies into the antipan-CD44 and anti-CD44-v6 subgroups, which were the major antibodies applied in these studies, for each organ. In oral cancer, pan-CD44 expression was not associated with OS rate, but high CD44 level did predict a better DFS rate $(R R=1.65,95 \%$ CI 1.68 - 2.13) [21,42]. Furthermore, a lower risk of lymph node metastasis was related with pan-CD44 expression in oral cancer patients $(\mathrm{RR}=0.58$, 95\% CI 0.37 - 0.92), but CD44-v6 expression did not reveal a similar correlation $(\mathrm{RR}=0.79,95 \% \mathrm{CI} 0.29-2.12)$. On the other hand, pan-CD44 and CD44-v6 expression were found to be related to higher $\mathrm{N}$ grade in laryngeal cancer patients (pan-CD44, RR = 2.83, 95\% CI $2.01-3.98$; CD44-v6 RR $=1.92$ 95\% CI 1.39-2.64), but neither panCD44 nor CD44-v6 expression showed a relationship with $\mathrm{T}$ grade or tumor grade in laryngeal or pharyngolaryngeal cancer patients (Additional file 4: Table S2). Furthermore, a poorer 5-year OS rate was associated with pan-CD44 and CD44-v6 expression both in laryngeal (CD44: RR = 0.66, 95\% CI 0.46 - 0.95; CD44-v6 RR = 0.53, 95\% CI 0.370.77 ) and pharyngolaryngeal cancer (CD44: $\mathrm{RR}=0.56$, 95\% CI 0.34 - 0.93; CD44-v6 RR =0.53, 95\% CI 0.37-0.77).

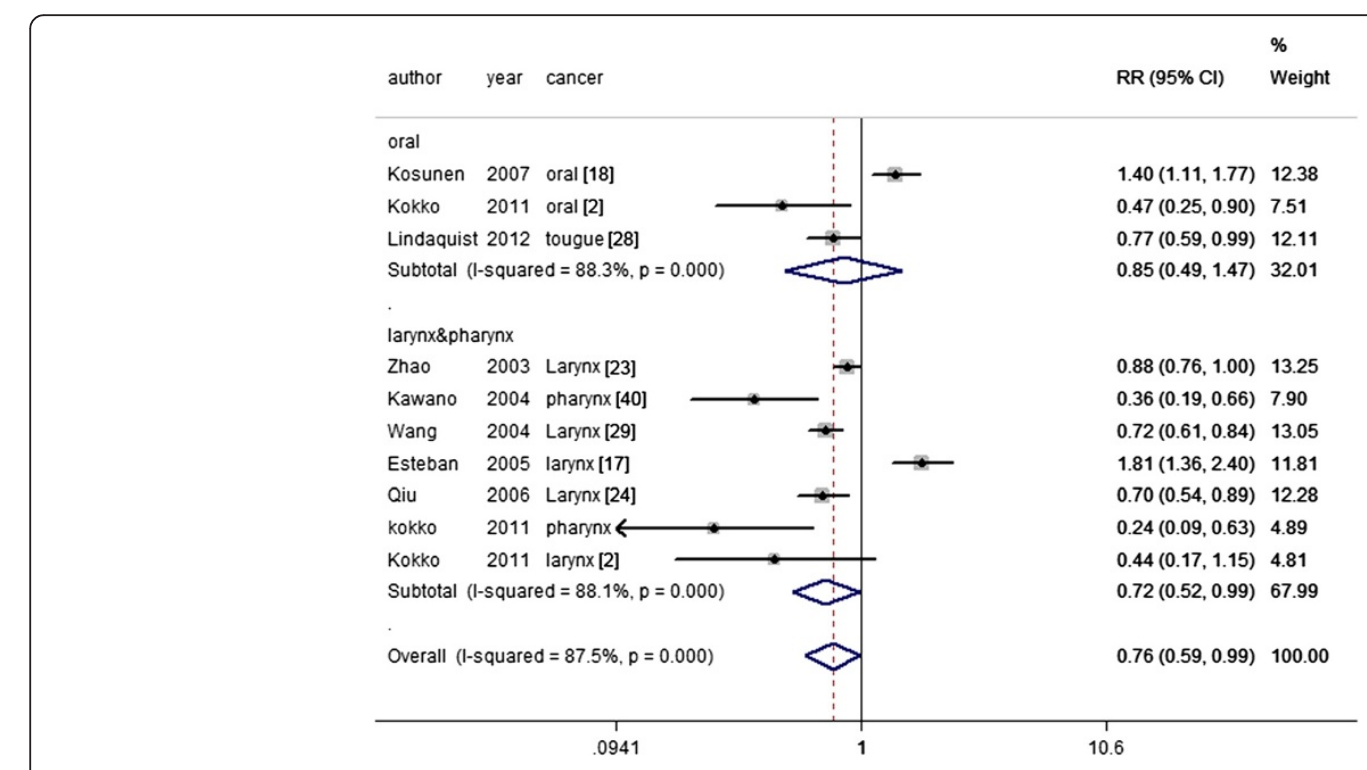

Figure 2 CD44 expression and 5-year OS rate stratified to oral and pharyngolaryngeal cancer. 


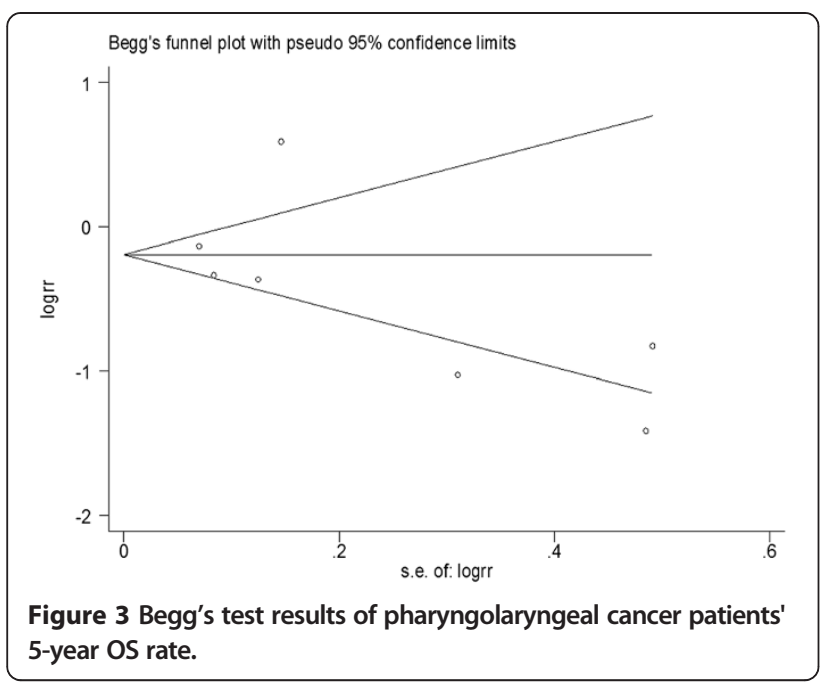

However, neither CD44 nor CD44-v6 was correlated with the 3-year OS rate in patients with laryngeal cancer, which implies that a longer follow-up time is needed for head and neck patients.

\section{Discussion}

CD44 is one of the most frequently observed cancer stem cell (CSC) markers in solid tumors, and it was revealed to be a target of the Wnt pathway [48], which is accepted as a main pathway for the stemness maintenance of CSCs, and usually accepted as a poor prognosis marker. However, most reports that used CD44 as a CSC marker used the pan-CD44 antibody, which recognizes all variants of CD44; thus, these studies provide limited knowledge about the relationship between specific CD44 variants and CSCs. Very recently, several studies found a distinct role between CD44v and CD44s. The EMT process in several epithelial cells was accompanied by a transition in CD44 isoforms from CD44v to CD44s, and CD44s has been shown to promote the EMT process $[49,50]$. However, hypoxia and hypoxiainducible factor- $1 \alpha$ have been shown to stimulate CD44v expression, sialyl Lewis $\mathrm{X}$ glycan has been found to attach to CD44v rather than to CD44s, and CD44v has been shown to be a ligand for E-selectin during tumor metastasis [51]. These findings indicate complicated roles of CD44s and CD44v in tumor progression. The expression of CD44 standard, v3, v5, v6, and v9 have been reported in HNSCC patients [36,37,46,52,53]. Of interest, we found that high CD44 expression in HNSCC patients indicated different clinical values in the oral cavity and pharynx or larynx. CD44 high expression strongly predict poorer $\mathrm{T}$ grade, $\mathrm{N}$ grade and worse overall survival rate in the larynx and pharynx, but better disease free survival rate and no association with any clinicopathological features in oral cancer. According to our systemic review results, CD44 expression may have a different prognostic value in the squamous cancer of the oral cavity and pharynx or larynx. To the best of our knowledge, there is still no direct explanation for this observation, so here, we mainly focused on the unexpected meta-analysis result and tried to give a rational explanation by reviewing the literature.

Although many of these works showed a negative relationship between CD44 protein level and prognosis in oral cancer patients, several reports found that an increased transcriptional level of CD44 indicated disease progression. Rajarajan et al. [54] found that the mRNA level of CD44 was significantly increased in oral squamous cell carcinomas; in addition, Lin et al. [55] revealed the CD44 mRNA levels in the peripheral blood of patients with locally advanced oral or oropharynx cancer were much higher than in healthy people, and a high CD44 mRNA level was significantly related to poor prognosis. This interesting phenomenon prompted us to review the antibodies applied by all of the studies in this metaanalysis. As different CD44 isoforms have distinct extracellular domains while retaining the same transmembrane and intracellular domain structure, nearly all works in this review used antibodies that targeted the extracellular domain of CD44. It is important to note that decreased intensity of CD44 by extracellular domain targeted antibody detection does not definitively indicate low CD44 expression because the shedding of CD44, which means the cutting off of the extracellular domain of CD44, could cause the false appearance of decreased CD44 expression. In fact, CD44 shedding has been observed in many human tumors, including breast, lung, colon and ovarian carcinomas [56], and indeed takes part in tumorigenesis and tumor metastasis. In the late phase of HA-CD44 binding, the CD44 at the leading edge of the cell is cleaved by a disintegrin and metalloproteinase domain (ADAM) protein and matrix metalloproteinase 14 (MMP14), and this cleavage is required for tumor cell migration [57]. Furthermore, researchers have found that the CD44 ectodomain cleavage subsequently induces the CD44 intramembranous cleavage, and the intramembranous cleavage generates the CD44 intracellular domain, which is translocated to the nucleus as a signal transduction molecule and activates the transcription of various genes, including CD44 [58,59]. This positive feedback loop supports our hypothesis that an increase in CD44 expression during oral cancer progression could be covered by its shedding.

The shedding of CD44 has been reported to be mainly associated with ADAM10 and ADAM17. ADAM10 is co-localized with CD44, and inhibition of ADAM10 could decrease the shedding of CD44 [60]. In oral cancer, it was shown that ADAM10 and ADAM17 expression were positively related to CD44 cleavage status; furthermore, 
both of them were more highly expressed in advanced oral cancer and were indicators of nodal metastasis [61-63]. However, little research on ADAM 10/17 could be found for pharyngolaryngeal cancer; therefore, we referred to the Oncomine database (www.oncomine.org). The results showed that, according to gene microarray analysis, ADAM10 was not increased in hypopharyngeal cancer compared to normal tissue [64] and that both ADAM10 and ADAM17 were not presented in the list of genes with significantly altered expression levels in pharyngolaryngeal cancer compared to normal tissue. Although these results were based on mRNA levels, they could also strongly indicate a difference in CD44 proteolytic enzyme expression between oral and pharyngolaryngeal cancer and may explain the different role of CD44 in the oral cavity and pharynx. With this in mind, we propose that future studies should evaluate the cleavage of CD44 rather than intact CD44 protein for prognosis prediction.

According to the analysis above, CD44 indeed participates in oral cancer progression, but cell staining of CD44 may not be accurate enough to reflect the authentic levels of CD44 because of the shedding of CD44. CD44 cleavage results in the extracellular epitope of CD44 being detached from the cell membrane and existing in its soluble form (sCD44). Although CD44 was widely expressed in normal oral mucosa, CD44 cleavage was found to occur at a low level or not at all in normal oral mucosa [65] and to be overexpressed in oral cancer tissue [61], which could be explained by the proteolytic effect of ADAM. Additionally, it was reported that the salivary SCD44 levels were much higher in HNSCC patients than in patients with benign disease [66,67]; however, the plasma level of sCD44 was not significantly different between oral cancer patients and normal controls, which may be attributed to the relatively small burden of oral tumors that may not alter the basal level of CD44 [66]. The same situation has been reported in gastrointestinal stromal tumors (GIST); CD44 cleavage activity was shown in $87.1 \%$ of GISTs but was absent in normal tissues, and increased CD44 cleavage was significantly related to advanced TNM stage and poor prognosis [68]. Here, we proposed that detecting the CD44 cleavage or soluble CD44 levels in tissue sections or oral rinses would be better than cell staining for prognostic prediction; another advantage of oral rinses is their convenience and noninvasiveness. Furthermore, based on the above discussion, CD44 may have limited utility in identifying oral CSCs [69], but some other cell surface markers have been reported to be expressed on stem-like cells in oral cancer, such as CD133, ABCG2 and ALDH1 [5,6]. In contrast, high CD44 expression was proven to be closely related to poor prognosis and was clearly enriched in stem-like cells in pharyngeal or laryngeal cancers [70-72].

Although we performed a comprehensive analysis of the association between CD44 expression and patient clinicopathological parameters for HNSCC, there were some limitations to this meta-analysis. First, the confounders were hard to control in the case-control studies, which may have affected the authentic prognostic value of CD44 expression. Second, except for CD44-v6, our systematic review and meta-analysis could not clarify the association between other CD44 variants and patient survival because of insufficient eligible information. Third, high quality studies with complete reports, including TNM stage and survival data, were limited, which may compromise our conclusions. In addition, there could be potential language bias in this meta-analysis because we only considered the literature written in English and Chinese. In conclusion, our systematic review and meta-analysis suggested that cell staining of CD44 has different prediction values for oral and pharyngolaryngeal cancer. In pharyngolaryngeal cancer, high CD44 staining intensity indicated worse $\mathrm{T}$ grade, worse $\mathrm{N}$ grade and a markedly shortened OS; meanwhile, cell staining of CD44 is not recommended for any clinicopathological or survival prediction for oral squamous cancer patients based on our review. The sCD44 evaluation may be a good substitute in oral cancer patients, and additional well-designed studies are needed to draw an authentic conclusion.

\section{Conclusion}

Our analysis indicated prognostic value of CD44 expression were different between laryngopharyngeal cancer and oral cancer, that CD44 related to worse T category, $\mathrm{N}$ category, tumor grade and prognosis in pharyngeal and laryngeal cancer, but no significant association was revealed between CD44 and oral cancer.

\section{Additional files}

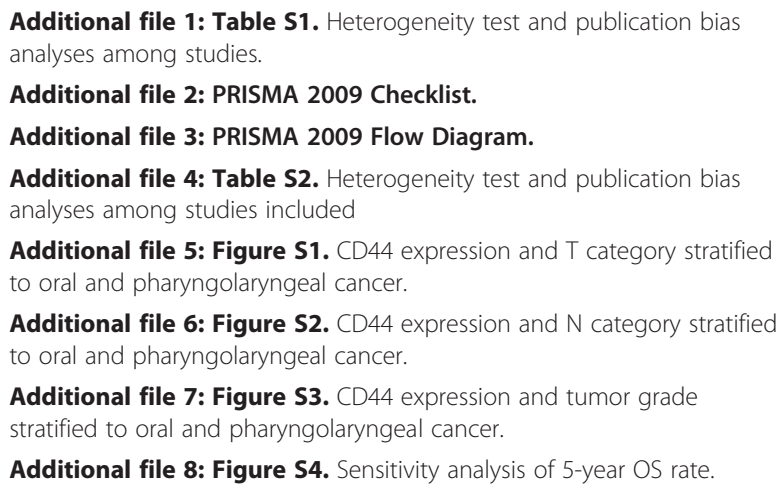

Additional file 5: Figure S1. CD44 expression and T category stratified to oral and pharyngolaryngeal cancer.

Additional file 6: Figure S2. CD44 expression and N category stratified to oral and pharyngolaryngeal cancer.

Additional file 7: Figure S3. CD44 expression and tumor grade stratified to oral and pharyngolaryngeal cancer.

Additional file 8: Figure S4. Sensitivity analysis of 5-year OS rate.

\section{Abbreviations}

HNSCC: Head and neck squamous cell carcinoma; Cl: Confidence interval; CSC: Cancer stem cell; IHC: Immunohistochemistry; OR: Odds ratio; OS: Overall survival; RR: Relative risk. 


\section{Competing interests}

The authors declare that they have no competing interests.

\section{Authors' contributions}

LG and JC participated in extracting the data and wrote the manuscript. JZ and $J L$ performed the statistical analysis. HX acbvnd XS carried out literature search and data collection. All authors approved the final manuscript.

\section{Acknowledgement}

This study is support by the Nature science foundation of Zhejiang Province (Grant No. LY12H13002), scientific project of CiXi (CN2013013), project of Zhejiang Traditional Chinese Medicine Administration (Grant No. 2012ZZ012), project of Zhejiang medical health science plan (Grant No. 2011KYA145), project of Zhejiang traditional Chinese medicine research (Grant No. 2013ZB115) and Nature science foundation of Ningbo City (Grant No. 2012A610205, 2012A610206)

Received: 21 November 2013 Accepted: 6 January 2014 Published: 13 January 2014

\section{References}

1. Siegel R, Naishadham D, Jemal A: Cancer statistics, 2012. CA: Canc J Clinician 2012, 62(1):10-29.

2. Kokko LL, Hurme S, Maula SM, Alanen K, Grenman R, Kinnunen I, Ventela S: Significance of site-specific prognosis of cancer stem cell marker CD44 in head and neck squamous-cell carcinoma. Oral Oncol 2011, 47(6):510-516.

3. Lobo NA, Shimono Y, Qian D, Clarke MF: The biology of cancer stem cells. Ann Rev Dev Biol 2007, 23:675-699.

4. Bomken S, Fiser K, Heidenreich O, Vormoor J: Understanding the cancer stem cell. Br J Canc 2010, 103(4):439-445.

5. Chiou SH, Yu CC, Huang CY, Lin SC, Liu CJ, Tsai TH, Chou SH, Chien CS, Ku $\mathrm{HH}$, LO JF: Positive correlations of Oct- 4 and Nanog in oral cancer stem-like cells and high-grade oral squamous cell carcinoma. Clin Canc Res: Offic J Am Assoc Canc Res 2008, 14(13):4085-4095.

6. Yu CC, Chang YC: Enhancement of cancer stem-like and epithelialmesenchymal transdifferentiation property in oral epithelial cells with long-term nicotine exposure: reversal by targeting SNAIL. Toxicol Appl Pharmacol 2013, 266(3):459-469.

7. Chen YS, Wu MJ, Huang CY, Lin SC, Chuang TH, Yu CC, LO JF: CD133/SrC axis mediates tumor initiating property and epithelial-mesenchymal transition of head and neck cancer. PloS One 2011, 6(11):e28053.

8. Trapasso S, Allegra E: Role of CD44 as a marker of cancer stem cells in head and neck cancer. Biol: Targets Ther 2012, 6:379-383.

9. Joshua B, Kaplan MJ, Doweck I, Pai R, Weissman IL, Prince ME, Ailles LE: Frequency of cells expressing CD44, a head and neck cancer stem cell marker: correlation with tumor aggressiveness. Head Neck 2012, 34(1):42-49.

10. Chikamatsu K, Takahashi G, Sakakura K, Ferrone S, Masuyama K: Immunoregulatory properties of CD44+ cancer stem-like cells in squamous cell carcinoma of the head and neck. Head \& neck 2011, 33(2):208-215.

11. van der Windt GJ, Schouten M, Zeerleder S, Florquin S, van der Poll T: CD44 is protective during hyperoxia-induced lung injury. Am J Respir Mol Biol 2011, 44(3):377-383.

12. Zoller M: CD44: can a cancer-initiating cell profit from an abundantly expressed molecule? Nat Rev Canc 2011, 11(4):254-267.

13. Negi LM, Talegaonkar S, Jaggi M, Ahmad FJ, labal Z, Khar RK: Role of CD44 in tumour progression and strategies for targeting. J Drug Target 2012, 20(7):561-573.

14. Aruffo A, Stamenkovic I, Melnick M, Underhill CB, Seed B: CD44 is the principal cell surface receptor for hyaluronate. Cell 1990, 61(7):1303-1313.

15. Orian-Rousseau V: CD44, a therapeutic target for metastasising tumours. Eur J Canc 2010, 46(7):1271-1277.

16. Wibulswas A, Croft D, Pitsillides AA, Bacarese-Hamilton I, McIntyre P, Genot E, Kramer IM: Influence of epitopes CD44v3 and CD44v6 in the invasive behavior of fibroblast-like synoviocytes derived from rheumatoid arthritic joints. Arthritis Rheum 2002, 46(8):2059-2064.

17. Fehon RG, McClatchey Al, Bretscher A: Organizing the cell cortex: the role of ERM proteins. Nat Rev Mol Cell Biol 2010, 11(4):276-287.
18. Lamontagne CA, Grandbois M: PKC-induced stiffening of hyaluronan/ CD44 linkage; local force measurements on glioma cells. Exp Cell Res 2008, 314(2):227-236.

19. Gonzalez-Moles MA, Bravo M, Ruiz-Avila I, Esteban F, Rodriguez-Archilla A, Gonzalez-Moles S, Arias B: Adhesion molecule CD44 as a prognostic factor in tongue cancer. Anticancer Res 2003, 23(6D):5197-5202.

20. Esteban F, Bravo JJ, Gonzalez-Moles MA, Bravo M, Ruiz-Avila I, Gil-Montoya JA: Adhesion molecule CD44 as a prognostic factor in laryngeal cancer. Anticancer Res 2005, 25(2A):1115-1121.

21. Kosunen A, Pirinen R, Ropponen K, Pukkila M, Kellokoski J, Virtaniemi J,

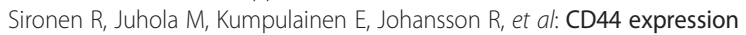
and its relationship with MMP-9, clinicopathological factors and survival in oral squamous cell carcinoma. Oral Oncol 2007, 43(1):51-59.

22. Wang SJ, Earle C, Wong G, Bourguignon LY: Role of hyaluronan synthase 2 to promote CD44-dependent oral cavity squamous cell carcinoma progression. Head Neck 2013, 35(4):511-520.

23. Mori S, Nose M, Morikawa H, Sato A, Saito T, Song ST, Tanda N, Teshima T: A novel evaluation system of metastatic potential of oral squamous cell carcinoma according to the histopathological and histochemical grading. Oral Oncol 1998, 34(6):549-557.

24. Wang S, Qiang Y, Xiao K, Jiang S, Chen E: Expression of CD44s and CD44v6 in laryngeal squamous cell carcinoma and their significance. J Clin Oto (China) 2000, 14(10):3.

25. Rong XZ, Zhi WS, Ming CX: The immunohistochemical expression of CD44s and CD44v6 in oral squamous cell carcinomas. J Oral Maxillofac Surg 2001, 11(3):208-211.

26. Zhao SW, Sun BC, He J, Ye Q, Lin SZ, Sun A: The expression of CD44 and its significance in human laryngeal carcinoma. J Clin Oto (China) 2003, 17(3):3.

27. Qiu XX, Huang JF, Zhang ZX, Da P, Zhou R: The expression of CD44 and its clinical significance in human laryngeal carcinoma. Med J Comm 2006, 20(6):670-671.

28. Lu S, Tian J, Lv Z, Wang H, Bai X, Liu W, Li J, Xu W: The probable role of tumor stem cells for lymph node metastasis in supraglottic carcinoma. Pathol Oncol Res: POR 2011, 17(1):33-38.

29. Uwa N, Kataoka TR, Torii I, Sato A, Nishigami T, Song M, Daimon T, Saeki N, Sagawa K, Mouri T, et al: CD44 expression is related to poor prognosis of hypopharyngeal squamous cell carcinoma. Acta Oto-laryngologica 2011, 131(3):323-329.

30. Yuce I, Bayram A, Cagli S, Canoz O, Bayram S, Guney E: The role of CD44 and matrix metalloproteinase- 9 expression in predicting neck metastasis of supraglottic laryngeal carcinoma. Am J Otolaryngol 2011, 32(2):141-146.

31. Lindquist D, Ahrlund-Richter A, Tarjan M, Tot T, Dalianis T: Intense CD44 expression is a negative prognostic factor in tonsillar and base of tongue cancer. Anticancer Res 2012, 32(1):153-161.

32. Wang $M$, Xing $L$, Zhang $C$ : Study in the Expression of CD44 in Nasopharyngeal Neoplasms and the Clinical Relationship. Tianjin Med J 2004, 32(9):3.

33. Song X, Peng J, Cai X, Hou F, Lin Q: Expression of CD44v6 protein in laryngeal squamous cell carcinoma. Chin J Otorhinolaryngol-Skull Base Surg 1999, 5(2):4

34. Xu YP, Zhao XQ, Sommer $K$, Moubayed P: Correlation of matrix metalloproteinase- $2,-9$, tissue inhibitor-1 of matrix metalloproteinase and CD44 variant 6 in head and neck cancer metastasis. J Zhejiang Univ (Sci) 2003, 4(4):491-501

35. Liqun X, Lijia S, Huiyong J, Liu Q: Tissue microarray assay of CD44v6 and PCNA expression for oral squamous cell carcinomas and precancerous lesions and it sclinical significance. J Jinan Univ 2006, 27(6):8.

36. Staibano S, Merolla F, Testa D, lovine R, Mascolo M, Guarino V, Castellone MD, Di Benedetto M, Galli V, Motta S, et al: OPN/CD44v6 overexpression in laryngeal dysplasia and correlation with clinical outcome. Brit J Canc 2007, 97(11):1545-1551.

37. Huang S, Luo W, Wu S, Wang W, Chen X: Expression of PCNA and CD44V6 in laryngeal carcinoma. J Guangdong Medical Coll 2007, 2(2):3.

38. Lu J, Gao Y, Xiao Y, Jin D: Expression and clinical significance of CD44v6 in tissues of laryngeal and hypopharyngeal squamous cell carcinoma. $J$ Harbin Med Univ 2008, 42(2):5.

39. Gao Y: The expression and its significance of CD44v6 in human laryngeal and hypopharyngeal squamous cell carcinoma. Chi Med Herald 2009, 6(1):2. 
40. Guo X, Li F X, Feng S, Li X, Pan Z, Guan C, Wang Y, Yang H, Jiang X: Expression of gene BRMS1 and CD44v6 protein in supraglottic laryngeal carcinoma and its clinical significance. J Clin Otorhinolaryngol Head Neck Surg (China) 2009, 23(6):6.

41. Zhang R, Fan LV, Mu S, Xie X, Zhang M, Zhao C, Chang Q: Expression of CD44v6 in human oral squamous cell carcinoma. J Oral Sci Res 2011, 27(9):4.

42. Masuda M, Kuratomi Y, Shiratsuchi H, Nakashima T, Naonobu K, Komiyama S: Decreased CD44H expression in early-stage tongue carcinoma associates with late nodal metastases following interstitial brachytherapy. Head Neck 2000, 22(7):662-665.

43. Kawano T, Nakamura Y, Yanoma S, Kubota A, Furukawa M, Miyagi Y, Tsukuda M: Expression of E-cadherin, and CD44s and CD44v6 and its association with prognosis in head and neck cancer. Auris Nasus Larynx 2004, 31(1):35-41.

44. Bankfalvi A, Krassort M, Buchwalow IB, Vegh A, Felszeghy E, Piffko J: Gains and losses of adhesion molecules (CD44, E-cadherin, and beta-catenin) during oral carcinogenesis and tumour progression. J Pathol 2002, 198(3):343-351.

45. Ma D, Yuan L, Zhao Y, Zhou X, Li C, Liu L: Relationship study between KAI1, CD44v3 expressions and laryngeal carcinoma. J Shandong Med Coll 2009, 31(2):4.

46. Ue T, Yokozaki H, Kagai K, Higashikawa K, Yasui W, Sugiyama M, Tahara E, Ishikawa T: Reduced expression of the CD44 variant exons in oral squamous cell carcinoma and its relationship to metastasis. J Oral Pathol Med: offi Publ Int Assoc Oral Pathol Am Acad Pathol 1998, 27(5):197-201.

47. Fonseca I, Pereira T, Rosa-Santos J, Soares J: Expression of CD44 isoforms in squamous cell carcinoma of the border of the tongue: A correlation with histological grade, pattern of stromal invasion, and cell differentiation. J Surg Oncol 2001, 76(2):115-120.

48. Kwong LN, Dove WF: APC and its modifiers in colon cancer. Adv Exp Med Biol 2009, 656:85-106.

49. Biddle A, Gammon L, Fazil B, Mackenzie IC: CD44 staining of cancer stemlike cells is influenced by down-regulation of CD44 variant isoforms and up-regulation of the standard CD44 isoform in the population of cells that have undergone epithelial-to-mesenchymal transition. PloS one 2013, 8(2):e57314.

50. Brown RL, Reinke LM, Damerow MS, Perez D, Chodosh LA, Yang J, Cheng C: CD44 splice isoform switching in human and mouse epithelium is essential for epithelial-mesenchymal transition and breast cancer progression. J Clin Investig 2011, 121(3):1064-1074.

51. Krishnamachary B, Penet MF, Nimmagadda S, Mironchik Y, Raman V, Solaiyappan M, Semenza GL, Pomper MG, Bhujwalla ZM: Hypoxia regulates CD44 and its variant isoforms through HIF-1alpha in triple negative breast cancer. PloS One 2012, 7(8):e44078.

52. Rodrigo JP, Dominguez F, Alvarez C, Herrero A, Suarez C: Expression of E-cadherin, CD44s, and CD44v6 in laryngeal and pharyngeal carcinomas. Am J Otolaryngol 2003, 24(6):384-389.

53. Piffko J, Bankfalvi A, Klauke K, Dreier R, Joos U, Bocker W, Schmid KW: Unaltered strong immunohistochemical expression of CD44-v6 and -v5 isoforms during development and progression of oral squamous cell carcinomas. J Oral Pathol Med: Offic Publ Int Ass Oral Pathologists Am Acad Oral Pathol 1996, 25(9):502-506.

54. Rajarajan A, Stokes A, Bloor BK, Ceder R, Desai H, Grafstrom RC, Odell EW: CD44 expression in oro-pharyngeal carcinoma tissues and cell lines. PloS One 2012, 7(1):e28776.

55. Lin JT, Chang TH, Chang CS, Wang WH, Su BW, Lee KD, Chang PJ: Prognostic value of pretreatment CD44 mRNA in peripheral blood of patients with locally advanced head and neck cancer. Oral Oncol 2010 46(5):e29-e33.

56. Okamoto I, Tsuiki H, Kenyon LC, Godwin AK, Emlet DR, Holgado-Madruga M, Lanham IS, Joynes CJ, Vo KT, Guha A, et al: Proteolytic cleavage of the CD44 adhesion molecule in multiple human tumors. Am J Pathol 2002, 160(2):441-447.

57. Stamenkovic I, Yu Q: Shedding light on proteolytic cleavage of CD44: the responsible sheddase and functional significance of shedding. J Investig Dermatol 2009, 129(6):1321-1324.

58. Okamoto I, Kawano Y, Murakami D, Sasayama T, Araki N, Miki T, Wong AJ, Saya H: Proteolytic release of CD44 intracellular domain and its role in the CD44 signaling pathway. J Cell Biol 2001, 155(5):755-762.

59. Lammich S, Okochi M, Takeda M, Kaether C, Capell A, Zimmer AK, Edbauer D, Walter J, Steiner $H$, Haass C: Presenilin-dependent intramembrane proteolysis of CD44 leads to the liberation of its intracellular domain and the secretion of an Abeta-like peptide. J Biol Chem 2002, 277(47):44754-44759.

60. Anderegg U, Eichenberg T, Parthaune T, Haiduk C, Saalbach A, Milkova L, Ludwig A, Grosche J, Averbeck M, Gebhardt C, et al: ADAM10 is the constitutive functional sheddase of CD44 in human melanoma cells. J Investig Dermatol 2009, 129(6):1471-1482.

61. Takamune $Y$, Ikebe T, Nagano O, Nakayama H, Ota K, Obayashi T, Saya H, Shinohara M: ADAM-17 associated with CD44 cleavage and metastasis in oral squamous cell carcinoma. Virchows Archiv: Int J Pathol 2007, 450(2):169-177.

62. Takamune $Y$, Ikebe T, Nagano $O$, Shinohara M: Involvement of NF-kappaBmediated maturation of ADAM-17 in the invasion of oral squamous cell carcinoma. Biochem Biophys Res Commun 2008, 365(2):393-398.

63. Ko SY, Lin SC, Wong YK, Liu CJ, Chang KW, Liu TY: Increase of disintergin metalloprotease 10 (ADAM10) expression in oral squamous cell carcinoma. Canc lett 2007, 245(1-2):33-43.

64. Cromer A, Carles A, Millon R, Ganguli G, Chalmel F, Lemaire F, Young J, Dembele D, Thibault C, Muller D, et al: Identification of genes associated with tumorigenesis and metastatic potential of hypopharyngeal cancer by microarray analysis. Oncogene 2004, 23(14):2484-2498.

65. Oliveira DT, Odell EW: Expression of CD44 variant exons by normal oral epithelia. Oral Oncol 1997, 33(4):260-262.

66. Franzmann EJ, Reategui EP, Pedroso F, Pernas FG, Karakullukcu BM Carraway KL, Hamilton K, Singal R, Goodwin WJ: Soluble CD44 is a potential marker for the early detection of head and neck cancer. Canc Epidemiol Biomark Preve: Publ Am Assoc Canc Res, Cosponsored Am Soc Prev Oncol 2007, 16(7):1348-1355.

67. Pereira LH, Adebisi IN, Perez A, Wiebel M, Reis I, Duncan R, Goodwin WJ, Hu J, Lokeshwar VB, Franzmann EJ: Salivary markers and risk factor data: a multivariate modeling approach for head and neck squamous cell carcinoma detection. Canc Biomarkers : Dection A of Dis markers 2011 10(5):241-249.

68. Hsu KH, Tsai HW, Lin PW, Hsu YS, Shan YS, Lu PJ: Clinical implication and mitotic effect of CD44 cleavage in relation to osteopontin/CD44 interaction and dysregulated cell cycle protein in gastrointestinal stromal tumor. Ann Surg Oncol 2010, 17(8):2199-2212.

69. Margaritescu C, Pirici D, Simionescu C, Stepan A: The utility of CD44, CD117 and CD133 in identification of cancer stem cells (CSC) in oral squamous cell carcinomas (OSCC). Romanian journal of morphology and embryology = Revue roumaine de morphologie et embryologie 2011, 52(3 Suppl):985-993.

70. Su J, Xu XH, Huang Q, Lu MQ, Li DJ, Xue F, Yi F, Ren JH, Wu YP. Identification of cancer stem-like CD44+ cells in human nasopharyngeal carcinoma cell line. Arch Med Res 2011, 42(1):15-21.

71. Lun SW, Cheung ST, Cheung PF, To KF, Woo JK, Choy KW, Chow C, Cheung CC, Chung GT, Cheng AS, et al: CD44+ cancer stem-like cells in EBV-associated nasopharyngeal carcinoma. PloS one 2012, 7(12):e52426.

72. Janisiewicz AM, Shin JH, Murillo-Sauca O, Kwok S, Le QT, Kong C, Kaplan MJ, Sunwoo JB: CD44(+) cells have cancer stem cell-like properties in nasopharyngeal carcinoma. Int Forum Allergy \& Rhinology 2012 2(6):465-470.

doi:10.1186/1471-2407-14-15

Cite this article as: Chen et al:: Significance of CD44 expression in head and neck cancer: a systemic review and meta-analysis. BMC Cancer 2014 14:15. 